\title{
Alarming endoscopic data in young and older asymptomatic people: Results of an open access, unlimited age colonoscopic screening for colorectal cancer
}

\author{
VASILEIOS PANTERIS ${ }^{1}$, NIKOLAOS VASILAKIS ${ }^{1}$, MARIA DEMONAKOU ${ }^{2}$, ELENI KORNAROU ${ }^{3}$, \\ EFTYXIOS KTENAS $^{3}$, EMANUELLA RAPTI ${ }^{1}$, GEORGE SPITHAKIS ${ }^{1}$, KONSTANTINA KATOPODI $^{1}$, \\ MARIA HORTI $^{2}$, STEFANI VGENOPOULOU ${ }^{2}$, JOHN TRIANTAFYLLIDIS ${ }^{4}$, \\ APOSTOLOS PAPALOIS $^{5}$ and PANAGIOTIS KARANTANOS ${ }^{1}$
}

\begin{abstract}
Departments of ${ }^{1}$ Gastroenterology and ${ }^{2}$ Histopathology, Sismanogleio-Amalia Flemig General Hospital, 15126 Athens; ${ }^{3}$ Department of Epidemiology and Biostatistics, National School of Public Health, 11521 Athens;

${ }^{4}$ Department of Gastroenterology, Metropolitan General, Hellenic Society of Gastrointestinal Oncology, 15562 Athens; ${ }^{5}$ Experimental, Educational and Research Center, ELPEN Laboratories, Hellenic Society of Gastrointestinal Oncology, 19009 Athens, Greece
\end{abstract}

Received July 29, 2019; Accepted November 4, 2019

DOI: $10.3892 / \mathrm{mco} .2019 .1967$

\begin{abstract}
There is a lack of a national organized screening program for colorectal cancer in Greece, and asymptomatic detection is usually the result of individual decisions. The collection of epidemiologic endoscopic data from a population of interest would therefore provide valuable information for future treatment guidance, especially during periods of economic austerity. The current cross-sectional study included 380 asymptomatic, average risk individuals undergoing screening colonoscopy for the first time, during the period of one year in a tertiary public hospital in Athens. Descriptive and analytic epidemiologic data were analyzed. The prevalence of adenomas and advanced lesions were compared between the younger and older cohort, and a regression model was applied for risk evaluation. The mean age of participants was 63 years, and $53 \%$ were male. A significant proportion of patients presented with polyps $(51.5 \%)$ and $25 \%$ of them had lesions in the proximal colon. The prevalence of adenomas and advanced adenomas was 29.5 and $11.8 \%$, respectively. Similar high prevalence rates of lesions were identified in the cohort of individuals $<50$ years of age and the older cohort ( $>50$ years of age). Regression models identified age, number and size of polyps as the major risk factors for the detection of adenomas. The increase of advanced lesions in the older and younger cohort requires confirmation by larger studies. Overall, the results of the present study indicate the requirement for a
\end{abstract}

Correspondence to: Dr Vasileios Panteris, Department of Gastroenterology, Sismanogleio-Amalia Flemig General Hospital, Kritonos 36, 15126 Athens, Greece

E-mail: vasileios.panteris@gmail.com

Key words: screening, colorectal cancer, colonoscopy, public health well-organized screening colonoscopy program starting from as early as 40 years of age. This program may confer an additional endoscopic burden with socioeconomic consequences in a country with limited health resources.

\section{Introduction}

Colorectal cancer (CRC) is the fourth most common and the third most fatal type of cancer in Greece equating similar ranking in United States and Western Europe. It is alarming that the reduction in incidence by $32 \%$ and in mortality by $34 \%$ during the period 2000-2013 that has been achieved in the US and to a similar degree in Western Europe, has not been accomplished in Greece (IARC-GLOBOCAN 2018) (1). Despite the fact that overall cancer age-standardized mortality declined in Greece during the aforementioned period, the colorectal cancer mortality has substantially increased from 2010 to $2016(2,3)$. It is not clear if this can be attributed to the economic crisis affecting Greece during the last decade but a negative impact on various aspects of the healthcare system (4) and lifestyle determinants (5), have been reported that might influence a variety of risk factors for the particular disease. The situation becomes more problematic since there has been a lack of an organized screening program implemented by Greek health authorities in contrast to most European countries during the last decade (6). Accordingly no rational recommendations exist for introduction of a national screening program in order to shift away from costly tertiary hospital-based treatments (7). As a result, opportunistic screening still serves as a model for prevention of colorectal cancer even today, despite the well-established fact that screening is the basic tool for reduction of CRC mortality (8), which efficiently detects early cancer and precancerous lesions with high sensitivity (9). It is accepted that early detection of malignancy is also beneficial for healthcare costs (10). 
Worldwide guidelines concerning screening $(11,12)$ have advocated an array of available tests for CRC prevention on asymptomatic individuals 50-75 years old. Colonoscopy is one of the screening methods in addition to fecal occult blood tests, sigmoidoscopy and CT colonography. Until 2009 the adoption of fecal tests for screening purposes in Greece was low ranging from 8.3 to $10.9 \%$ in a population sample during a national household survey (13). Uptake of colonoscopy as a screening modality in Greece has a low acceptance as well, as it was shown by a sample of hospital employees from whom only $17 \%$ reported being submitted to screening colonoscopy (14).

Despite encouraging results of screening on CRC incidence and mortality for the population over 50 years of age, it also seems that adults below this age limit are reported to have substantial and increasing rates of CRC according to recent cancer statistics from the USA (1). Similar trends were observed in the Greek population stemming from vital registration data, as individuals 15-49 years old demonstrated increased CRC mortality rates after 2000 and a rate difference of 5.9\% has been documented after 2010 (3).

In Greece so far, there is no study addressing colorectal screening issues in the field of real-life endoscopy, collecting information for possible recommendations regarding the extend of health needs, in a period of restricted health budgets. This study presents the results of an open access, unlimited age colorectal colonoscopy screening based on personal demands, run in a tertiary public hospital of an urban area of Athens. The purpose of the study was to describe analytical epidemiological colonoscopic data over a wide age range of individuals and attempt to make comparisons between different age groups in order to identify possible targets of screening recommendations.

\section{Materials and methods}

This is a cross-sectional study which included white-caucasian individuals sequentially attending the outpatient endoscopy unit of a tertiary hospital center to undergo screening colonoscopy for colorectal cancer during the period of one year, from January until December 2017. As there are no national guidelines, screening colonoscopy was performed after an individual request on a free access basis. Only asymptomatic, average-risk persons, who completed the examination for the first time, were included in the study. Exclusion criteria were a personal or family history of colorectal cancer or adenomas, positive fecal occult blood tests (FOBT), existence of symptoms pertaining to the digestive system (specifically unrelenting abdominal pain, blood per rectum, chronic diarrhea, loss of body weight), chronic inflammatory bowel disease and iron-deficiency anemia. These patients are considered high risk in respect to colon cancer prevalence, thereby increasing risk above average. All procedures were performed with high definition Fujinon series endoscopes. The bowel cleaning was done using polyethylene glucol regimens of various molecular weights (marcogol 3,350, and 4,000) and was graded in a three class scale (good, adequate, poor) similar to Boston Preparation Scale. The detection of polyps during the examination was followed by polypectomy either during the same session or in a second session if certain precautions had to be taken because of the size or other polyp characteristics. There was a real-time estimation of the size of the polyps using the opening of the biopsy forcep $(7 \mathrm{~mm})$ as a gold standard. The resection was accomplished by hot or cold snare and biopsy on the discretion of the endoscopist. After excision, the polyps were put in different jars containing formaldehyde unless there were multiple diminutive ones, in which case the polyps from the same colon segment were contained in the same jar. The specimens were sent to the Department of Histopathology for further evaluation by experienced pathologists using the Vienna classification for dysplasia. Advanced adenomas (AA) were defined as those measuring more than $10 \mathrm{~mm}$ or with high grade dysplasia and/or intramucosal cancer. Serrated lesions were categorized as either non-neoplastic hyperplastic polyps, or as serrated sessile polyps (SSA/P) and traditional serrated adenomas (TSA), which were classified together. The endoscopists performing the colonoscopies were of varying experience including consultants, locum consultants, registrars and trainees under supervision. Data were collected from endoscopy and pathology reports while information about smoking habits, body mass index (BMI) or alcohol consumption were not available. The distribution of the polyps was categorized according to location into proximal colon up to the splenic flexure and distal colon. If a person had more than one polyp, the classification was based on the size of the largest polyp.

All participants provided written informed consent. The study has been performed in accordance with the Ethical standards of the 1964 Declaration of Helsinki and its later amendments. The Institutional Review board has approved the study protocol as well as the boards of the National School of Public Health and the Hellenic Society of Gastrointestinal Oncology.

Statistical analysis. The analysis was made per patient. The prevalence of non-neoplastic lesions, adenomas, high grade dysplasia (HGD), advanced adenomas and cancer was presented. Continuous variables were presented as mean with standard deviation (SD). Comparisons were examined using the independent t-test for continuous variables and the Pearson's correlation or Fischer's exact test for categorical variables. Analysis of variance was used when explanatory variables were categorical with more than two classes. Post hoc analysis for multiple comparisons between groups was produced using the least significance difference (LSD). The number needed to screen (NNS, the number of individuals that need to undergo colonoscopy in order to detect a precancerous lesion) was calculated. Independent risk factors for finding an adenoma was determined by logistic regression model with stepwise insertion of proposed variables according to significance level after crosstabulation. The 0.05 limit was set for statistical significance level. The SPSS 12 (SPSS, Inc.) was used for statistical analysis.

\section{Results}

A total of 380 individuals fulfilling the inclusion criteria were admitted for screening. The mean age was 63 years old (SD: 11 years, range: $30-87$ years). The male/female ratio was $53.2 / 46.8 \%$ (202/178). The bowel cleaning was regarded as 'good' in $64.7 \%$ of the participants. The completion rate to the 
Table I. Basic demographics of participants.

\begin{tabular}{|c|c|}
\hline Characteristic & $\begin{array}{c}\text { Demographics, } \\
\mathrm{n}=380(\%)\end{array}$ \\
\hline Age mean (years, standard deviation) & $63(11.1)$ \\
\hline Male/Female (\%) & $202 / 178(53.3 / 46.8)$ \\
\hline \multicolumn{2}{|l|}{ Prevalence of lesions (\%) } \\
\hline Any polyp & $197(51.8)$ \\
\hline Adenomas & $112(29.5)$ \\
\hline Advanced adenomas & $45(11.8)$ \\
\hline Cancer & $8(2.1)$ \\
\hline Low grade dysplasia & $101(26.6)$ \\
\hline High grade dysplasia & $20(5.3)$ \\
\hline Hyperplastic polyps & $107(28.2)$ \\
\hline Serrated polyps & $24(6.3)$ \\
\hline \multicolumn{2}{|l|}{ Polyp shape (\%) } \\
\hline Penduculated & $40(10.5)$ \\
\hline Sessile & $102(26.8)$ \\
\hline Flat & $100(26.3)$ \\
\hline \multicolumn{2}{|l|}{ Polyp size, mm } \\
\hline$\leq 5$ & $154(40.5)$ \\
\hline $6-10$ & $184(48.4)$ \\
\hline $11-20$ & $29(7.6)$ \\
\hline $21-40$ & $8(2.1)$ \\
\hline \multicolumn{2}{|l|}{ Polyp location (\%) } \\
\hline Proximal colon & $91(23.9)$ \\
\hline \multicolumn{2}{|l|}{ According to maximum polyp size, $\mathrm{mm}$} \\
\hline$\leq 5$ & 4 \\
\hline $6-10$ & 160 \\
\hline $11-20$ & 28 \\
\hline $21-40$ & 5 \\
\hline
\end{tabular}

Villous component of polyps is not included in advanced adenoma definition because it has been excluded as an independent variable in multivariate analysis (38).

cecum was achieved in $92 \%$ of the cases. The $74.5 \%$ of the examinations were performed by a specialized endoscopist and the rest were executed by trainees under supervision. The overall adenoma detection rate (ADR) was $28 \%$.

The prevalence of polyps, adenomas, advanced adenomas and cancer in the entire cohort was 51.8, 29.5, 11.8 and $2.1 \%$, respectively. Two hundred and sixty nine polyps were detected in total with a mean number of 2.5 polyps/person. Dysplasia was characterized as low grade (LGD) in $26.6 \%$ of the participants and as high grade (HGD) in $5.3 \%$. The prevalence of hyperplastic and serrated polyps was 28.2 and $6.3 \%$, respectively. Polyps were detected in the proximal colon in $23.9 \%$ of the colonoscopies. Details on demographics and polyp characteristics are presented in Table I.

When participants were stratified according to maximum polyp size and comparisons were made between the groups with adequate numbers for meaningful inferences, that was 6-10 vs. 11-20 $\mathrm{mm}$, it was shown that the larger polyp group presented more adenomas ( 51.3 vs. $89.3 \%, \mathrm{p}=0.0001)$, high grade dysplasia ( 7.5 vs. $25 \%, \mathrm{p}=0.01)$, advanced adenomas
Table II. Characteristics of colorectal lesions according to participants with largest lesion size.

\begin{tabular}{lrccc}
\hline & \multicolumn{4}{c}{ Maximum polyp size, mm } \\
\cline { 2 - 5 } Characteristic & $\leq 5$ & $6-10$ & $11-20$ & \\
$21-40$ & & & & \\
\hline No participants & 4 & 160 & 28 & 5 \\
Age, mean, years & 52 & 64.2 & 67 & 75.6 \\
Sex, male (\%) & 25 & 60 & 71.4 & 80 \\
Prevalence of lesions (\%) & & & & \\
Adenoma & 0 & 51.3 & 89.3 & 100 \\
AA & 0 & 8.1 & 96.4 & 100 \\
HGD & 0 & 7.5 & 25 & 20 \\
Cancer & 0 & 1.3 & 3.6 & 20 \\
Hyperplastic & 100 & 57.5 & 35.7 & 20 \\
Serrated & 0 & 12.5 & 14.3 & 0 \\
Proximal colon\% & 25 & 43.1 & 60.7 & 80 \\
\hline
\end{tabular}

(8.1 vs. $96.4 \%, p=0.0001)$ and location at the proximal colon (43.1 vs. $63.7 \%, \mathrm{p}=0.085)$. If we include all groups in the analysis, there is a significant trend for the presence of cancer as individuals acquire larger polyp sizes $(\mathrm{p}=0.048)$. The characteristics of participants according to largest lesion size are presented in Table II. Notably, the people with small polyps $(6-10 \mathrm{~mm})$ who are the largest group, present with high proportions of colorectal lesions from adenomas to advanced dysplasia or cancer and near half of them harbor lesions in the right colon.

Subgroup analysis of younger participants $(<50$ years of age) showed interesting results (Table III). The individuals 30-49 years old had a mean age of 42.5 years and $42.6 \%$ were male. Their screening colonoscopies have revealed high rates of adenomas, advanced adenomas, high grade dysplasia and cancer at the level of 10.6, 8.5, 5.1 and 2.1\%, respectively. All polyps in the younger cohort had size up to $20 \mathrm{~mm}$. These results indicate that younger participants although quantitatively have fewer lesions, the prevalence of advanced lesions is proportionally similar to the older cohort without difference between sexes (male ratio younger vs. older cohort, 42.6 vs. $54.7 \%, \mathrm{p}=0.12$ ).

Another finding is that the majority of participants with advanced adenomas had these lesions in the proximal colon compared with the left $(29 / 45,64.4 \%, p=0.0001)$. Among participants with polyps (no 197), those that harbor advanced adenomas, were predominantly male (75.6 vs. $57.2 \%$, $\mathrm{p}=0.027$ ), with more polyps/person (3.4 vs. 2.2, $\mathrm{p}=0.005)$, presented with more adenomas ( 93.3 vs. $46 \%, \mathrm{p}=0.0001)$, had more lesions in the proximal colon ( 64.4 vs. $40.8 \%, \mathrm{p}=0.005)$ and a trend to more cancer cases ( 4.4 vs. $1.3 \%, p=0.22)$. In 30-49 y individuals, the majority of advanced adenomas were also located at the proximal colon (75\% right vs. left $25 \%$, $\mathrm{p}=0.008$ ). The experienced endoscopists detected more polyps up to $10 \mathrm{~mm}$ in size located at the proximal colon than trainees (50.7 vs. $31.4 \%, \mathrm{p}=0.008)$.

Based on these results the clinically important number needed to screen to detect one patient with at least one adenoma 
Table III. Comparison between 30-49 and 50 years old participants.

Comparison between $30-49$ years and $\geq 50$ years old participants

\begin{tabular}{|c|c|c|c|c|}
\hline \multirow[b]{2}{*}{ Characteristics } & \\
\hline & $30-49$ years & $\geq 50$ years & OR $(95 \% \mathrm{CI})$ & P-value \\
\hline Number of participants & 47 & 333 & & \\
\hline Age, mean (SD, 95\% CI) & $42.5(5.9,40.8-44.1)$ & $65.9(8.3,65-66.7)$ & & 0.0001 \\
\hline \multicolumn{5}{|l|}{ Sex } \\
\hline Male (\%) & 42.6 & 54.7 & $0.61(0.33-1.13)$ & 0.12 \\
\hline \multicolumn{5}{|l|}{ Prevalence of lesions (\%) } \\
\hline Polyps & $16(34)$ & $181(54.4)$ & $0.43(0.22-0.82)$ & 0.009 \\
\hline Polyps/person (SD, 95\% CI) & $2.38(1.7,1.9-2.8)$ & $2.1(2.2,1.91-2.38)$ & & 0.8 \\
\hline Adenomas & $5(10.6)$ & $107(32.1)$ & $0.25(0.09-0.65)$ & 0.002 \\
\hline Advanced adenomas & $4(8.5)$ & $41(12.3)$ & $0.66(0.2-1.9)$ & 0.63 \\
\hline HGD & $3(6.4)$ & $17(5.1)$ & $1.26(0.35-4.5)$ & 0.72 \\
\hline Cancer & $1(2.1)$ & $7(2.1)$ & $1.01(0.12-8.4)$ & 0.9 \\
\hline Hyperplastic polyps & $14(30)$ & $93(27.9)$ & $1.09(0.5-2.1)$ & 0.7 \\
\hline Serrated polyps & 0 & $24(7.2)$ & $\mathrm{n} / \mathrm{a}$ & $0.09^{\mathrm{a}}$ \\
\hline Proximal colon & $7(15)$ & $84(25.2)$ & $0.51(0.22-1.2)$ & 0.12 \\
\hline
\end{tabular}

SD, standard deviation. ${ }^{\mathrm{a}}$ Fisher exact test.

Table IV. Logistic regression analysis of risk factors associated with adenoma finding.

\begin{tabular}{lcc}
\hline Risk factors & OR $(95 \% \mathrm{CI})$ & P-value \\
\hline Age & $1.086(0.74-1.57)$ & 0.0001 \\
No polyps & $1.19(0.20-6.95)$ & 0.04 \\
Maximum polyp size & 1.00 & \\
$1-10 \mathrm{~mm}$ & $8.43(2.32-30.5)$ & 0.003 \\
$11-40 \mathrm{~mm}$ & \\
\hline
\end{tabular}

OR, odds ratio.

or one advanced adenoma is $\mathrm{NNS}=3$ and $\mathrm{NNS}=8$, respectively. In the younger cohort 30-49 $\mathrm{y}$, the respective numbers are $\mathrm{NNS}=9$ and $\mathrm{NNS}=12$ for adenomas and advanced adenomas.

The multivariate analysis by logistic regression has revealed that age, number and size of polyps as documented by maximum polyp size were the only independent predictors for the finding of adenomas (Table IV). Sex and location in the proximal colon were not independent risk factors due to collinearity with age and proximal location with number of polyps as well.

\section{Discussion}

Prospective studies have demonstrated that colorectal cancer screening with colonoscopy is beneficial in respect to reduction in CRC mortality and incidence ranging from 29 to $65 \%$ and 48 to $67 \%$, respectively (8). Colonoscopy as a screening modality has achieved high sensitivity rates for the detection of adenomas $\geq 6 \mathrm{~mm}$ and advanced adenomas up to the level of 93 and $98 \%$, respectively (9). There is data reporting on screening outcomes for the asymptomatic, average risk individuals, originating from USA, Europe, Middle-East and East Asia (15-19) indicating prevalence rates lower than the present study, although differences do exist in the populations studied. Adenomas, advanced adenomas and advanced neoplasia (AA plus invasive cancer) prevalence rates are ranging from 12.3-29, 3.7-7.1 and 2.5-7.8\%, respectively. In Greece, CRC screening is opportunistic and mainly based on colonoscopy as it is the case in USA. One study published from a USA screening program (16) with a similar design and patients' demographics for the white population group, spanning from 2006 to 2010, reports adenoma and advanced adenoma rates of 19 and $3.7 \%$, respectively, which are lower than our study. It should be noted however that the American study included only persons over 50 years of age.

Asymptomatic, average risk individuals 30-49 y in our cohort were found to have high polyp, advanced adenomas, HGD, and cancer prevalence rates. This young cohort seems to have acquired similar risk rates present in older participants approximately two decades earlier. In literature, studies addressing similar issues in young participants mainly 40-49 years old, have provided lower prevalence rates of $15 \%, 1-2.5 \%$ and up to $0.2 \%$ for polyps, advanced adenomas and cancer, respectively (20-25). Some of these studies have concluded that screening below age $50 \mathrm{y}$ is not warranted in the general population based on their low prevalence of premalignant and advanced lesions. The prevalence noticed in this young Greek cohort is alarming as advanced lesions developed at this age will probably be transformed to cancer during the next decade $(26,27)$. These results if confirmed by larger cohorts may reduce the recommended age for screening colonoscopy by at least one decade. It is also implied that a significant burden will be added to an already devastated healthcare system following the economic restrictions. 
Serrated polyps are recently considered as the precursor lesions for an alternative to the classic adenoma-carcinoma sequence pathway that is responsible for $10-20 \%$ of cancer formation. Hyperplastic polyps, SSA/Ps and TSAs with somehow different molecular and clinical pathology are included in this particular group of serrated lesions (28). In this study, the prevalence of SSA/P and TSA overall, is slightly increased $(6.3 \%)$ as the literature reports rates of 4.8 and $5.6 \%$ from Europe and Asia (29,30). In addition, there were no premalignant serrated polyps discovered in younger individuals 30-49 y. This is in accordance with molecular studies that consider young cancer patients to have CIMP-low tumors unless they present with the Lynch syndrome (31).

Another point that needs attention is the high proportion of participants with small 6-9 $\mathrm{mm}$ polyps as the maximum polyp size. Although polyp size is a major risk factor for cancer development especially when exceeds $10 \mathrm{~mm}$, as already shown in this study, nonetheless the small polyps showed high rates of advanced lesions in this cohort. A systematic review including studies from 2003 to 2009 of asymptomatic screening individuals have revealed advanced adenomas and cancer prevalence rates in 6-9 mm polyps of 4.9 and $0.07 \%$ (32). It is not clear if our present findings constitute a characteristic of the specific population sample or signify a wider trend in cancer biology and progression in our country that would prove to be an ominous future. Assuming a progression rate of 3.5\%/year for advanced adenomas to become cancer (33) and an overall prevalence of AA in this cohort of $11.8 \%$ from which $30 \%$ are small polyps, it can be deducted that the 5 year CRC risk for 6-9 $\mathrm{mm}$ polyps is $0.62 \%$.

This study has certain limitations. The small sample size can serve as a potential limitation, so as a type II error cannot be excluded. This limitation is particularly relevant in respect to the younger cohort. Participants visiting public tertiary hospitals for screening purposes could be regarded as more health orientated, or may be driven by other comorbidities or even shifted to the public sector because of limited economic resources due to Greek financial austerity (4). The latter may merely be a reflection of socioeconomic status which is known to influence screening participation and outcomes $(7,33)$. These limitations may imply that our sample may not be representative of our general population although this risk is inherent to all studies that are hospital-based. The bowel preparation of the participants was proportionally suboptimal based on quality standards for colonoscopy $(12,34)$. This could have led to underestimation of results. Fortunately cecum intubation rate was within the proposed European standards for screening colonoscopies (set at 90\%) and ADR as well (set at $25 \%$ overall) (12) which might in part have counterbalanced the defected bowel preparation. A further drawback of the study is the fact that in organized screening programs, colonoscopies should be executed by certified-board endoscopists (35). In our setting, there were trainees involved in the procedure that although supervised could potentially lead to suboptimal examinations by strict criteria. Nonetheless the overall ADR of the colonoscopies with participation of trainees did not differ from that of their specialized colleagues (ADR: 28.8 vs. 28.2, respectively). An additional limitation is that data referring to well known risk factors for colorectal cancer (26) such as smoking, obesity and dietary habits are missing. Since these risk factors considerably vary among different populations, we feel that our findings also justify an extensive future work on these factors as it is likely that they might be partly responsible for the alarming results in our younger persons. Interestingly, a recently published study on the impact of financial crisis in social health factors among older adults in the Mediterranean region including many Greek islands and seaside territories, has reported up to $50 \%$ deterioration of the lifestyle health determinant score which is based on traits like smoking, alcohol consumption and depression. The Mediterranean diet adherence and physical activity were also affected by the economic deprivation (5). However it should be noted that the time duration of the crisis is relatively small, for the possible consequences to have become evident in the adenoma-carcinoma sequence.

The increased prevalence of colorectal lesions could also be postulated to be attributable to the ageing of the Greek population since age is considered a risk factor for CRC (26). The higher life expectancy at birth nowadays combined with the emigration of younger professionals known as brain drain (3) leads to accumulation of older individuals that could potentially have affected outcomes. However the growing incidence of advanced lesions in the younger participants, emphasize the fact that increased life expectancy is not the exclusive determinant of cancer prevalence. Rising incidence of CRC for individuals $<50$ years has been noticed also in other countries including USA, Australia, Canada and Norway. Although reasons for this discrepancy are not fully elucidated, it has been postulated to be attributable to unhealthy diet, obesity and sedentary lifestyle (1). Nonetheless, the high rates of precancerous lesions found in this report can justify the increasing mortality rates of CRC in Greece in contrast to other Western countries.

To the best of our knowledge, this is the first study analyzing screening epidemiological data from field endoscopy under the present prevailing conditions in Greece. The screening model is currently opportunistic based on individual demands and colonoscopies are partially reimbursed by the National Organization for the Provision of Primary Healthcare Services (EOPYY) if the patient is addressing the private sector or fully covered by National Health Security in public hospitals irrespective of employment status $(4,7)$.

In conclusion, the most disturbing finding is the magnitude of adenoma detection in the whole sample and the proportion of advanced lesions in our young cohort that if confirmed by larger studies conducted in other Greek hospitals, indicates that an organized screening endoscopic program is urgently required. More so as a study has suggested that a NNS $\leq 25$ is a cost effective threshold for colonoscopic detection of advanced adenomas (22), while our results have found a $\mathrm{NNS}=8$ and NNS=12 for the detection of advanced adenomas for the overall and younger cohort, respectively. Moreover, since most of the dangerous lesions are beyond the reach of sigmoidoscopy which is considered less costly and risky than colonoscopy (36), then any endoscopic screening program should employ and compensate mainly for colonoscopies in order to decrease the proportion of significant proximal missed lesions (37). This is especially important for the younger individuals due to the anticipated life expectancy. This conclu- 
sion is not deterrent for any screening program that employs other acceptable screening methods, such as FOBT.

\section{Acknowledgements}

Not applicable.

\section{Funding}

No funding was received.

\section{Availability of data and materials}

The datasets used and/or analyzed during the present study are available from the corresponding author on reasonable request.

\section{Authors' contribution}

PV, KJT, AP and PK conceived and designed the study and drafted the article. VP, NV, MD, EKo, EKt, ER, GS, KK, MH and SV analyzed and interpreted the data. EKo, EKt, KJT, AP and PK critically revised the article for important intellectual content and provided final approval of the manuscript. All authors agree to be accountable for all aspects of the work. All authors read and approved the final manuscript.

\section{Ethics approval and consent to participate}

The study has been performed in accordance with the Ethical standards of the 1964 Declaration of Helsinki and its later amendments. The Institutional Review board has approved the study protocol as well as the boards of the National School of Public Health and the Hellenic Society of Gastrointestinal Oncology.

\section{Patient consent for publication}

All participants provided written informed consent for publication.

\section{Competing interests}

The authors declare that they have no competing interests.

\section{References}

1. Siegel RL, Miller KD, Fedewa SA, Ahnen DJ, Meester RGS, Barzi A and Jemal A: Colorectal cancer statistics, 2017. CA Cancer J Clin 67: 177-193, 2017.

2. Laliotis I, Ioannidis JPA and Stavropoulou C: Total and cause-specific mortality before and after the onset of the Greek economic crisis: An interrupted time-series analysis. Lancet Public Health 1: e56-e65, 2016.

3. Global Burden of Disease 2016 Greece Collaborators: The burden of disease in Greece, health loss, risk factors, and health financing, 2000-16: An analysis of the Global Burden of Disease Study 2016. Lancet Public Health 3: e395-e406, 2018.

4. Simou E and Koutsogeorgou E: Effects of the economic crisis on health and healthcare in Greece in the literature from 2009 to 2013: A systematic review. Health Policy 115: 111-119, 2014.

5. Foscolou A, Tyrovolas S, Soulis G, Mariolis A, Piscopo S, Valacchi G, Anastasiou F, Lionis C, Zeimbekis A, Tur JA, et al: The impact of the financial crisis on lifestyle health determinants among older adults living in the mediterranean region: The multinational MEDIS study (2005-2015). J Prev Med Public Health 50: 1-9, 2017
6. Navarro M, Nicolas A, Ferrandez A and Lanas A: Colorectal cancer population screening programs worldwide in 2016: An update. World J Gastroenterol 23: 3632-3642, 2017.

7. Skroumpelos A, Zavras D, Pavi E and Kyriopoulos J: Recommending organized screening programs for adults in Greece: A Delphi consensus study. Health Policy 109: 38-45, 2013.

8. Armaroli P, Villain P, Suonio E, Almonte M, Anttila A, Atkin WS, Dean PB, de Koning HJ, Dillner L, Herrero R, et al: European code against cancer, 4th Edition: Cancer screening. Cancer Epidemiol 39 (Suppl 1): S139-S152, 2015.

9. Lin JS, Piper MA, Perdue LA, Rutter CM, Webber EM, O'Connor E, Smith N and Whitlock EP: Screening for colorectal cancer: Updated evidence report and systematic review for the US preventive services task force. JAMA 315: 2576-2594, 2016.

10. Chen PC, Lee JC and Wang JD: Estimation of life-year loss and lifetime costs for different stages of colon adenocarcinoma in taiwan. PLoS One 10: e0133755, 2015.

11. Rex DK, Boland CR, Dominitz JA, Giardiello FM, Johnson DA, Kaltenbach T, Levin TR, Lieberman D and Robertson DJ: Colorectal cancer screening: Recommendations for physicians and patients from the U.S. Multi-society task force on colorectal cancer. Gastroenterology 153: 307-323, 2017.

12. Rembacken B, Hassan C, Riemann JF, Chilton A, Rutter M, Dumonceau JM, Omar M and Ponchon T: Quality in screening colonoscopy: Position statement of the European society of gastrointestinal endoscopy (ESGE). Endoscopy 44: 957-968, 2012.

13. Dimitrakaki C, Boulamatsis D, Mariolis A, Kontodimopoulos N, Niakas D and Tountas Y: Use of cancer screening services in Greece and associated social factors: Results from the nation-wide hellas health I survey. Eur J Cancer Prev 18: 248-257, 2009.

14. Michopoulos S, Manios E, Kourkoutas H, Argyriou K, Leonidakis G, Zampeli E, Stamatelopoulos K and Dimopoulos AM: Predictors of colorectal cancer screening awareness among people working in a hospital environment. Ann Gastroenterol 30: 315-321, 2017.

15. Schroy PC III, Coe A, Chen CA, O'Brien MJ and Heeren TC: Prevalence of advanced colorectal neoplasia in white and black patients undergoing screening colonoscopy in a safety-net hospital. Ann Intern Med 159: 13-20, 2013.

16. Lebwohl B, Capiak K, Neugut AI and Kastrinos F: Risk of colorectal adenomas and advanced neoplasia in Hispanic, black and white patients undergoing screening colonoscopy. Aliment Pharmacol Ther 35: 1467-1473, 2012.

17. Yang MH, Rampal S, Sung J, Choi YH, Son HJ, Lee JH, Kim YH, Chang DK, Rhee PL, Rhee JC, et al: The prevalence of colorectal adenomas in asymptomatic Korean men and women. Cancer Epidemiol Biomarkers Prev 23: 499-507, 2014.

18. Boursi B, Halak A, Umansky M, Galzan L, Guzner-Gur H and Arber N: Colonoscopic screening of an average-risk population for colorectal neoplasia. Endoscopy 41: 516-521, 2009.

19. Bokemeyer B, Bock H, Hüppe D, Düffelmeyer M, Rambow A, Tacke W and Koop H: Screening colonoscopy for colorectal cancer prevention: Results from a German online registry on 269000 cases. Eur J Gastroenterol Hepatol 21: 650-655, 2009.

20. Strul H, Kariv R, Leshno M, Halak A, Jakubowicz M, Santo M, Umansky M, Shirin H, Degani Y, Revivo M, et al: The prevalence rate and anatomic location of colorectal adenoma and cancer detected by colonoscopy in average-risk individuals aged 40-80 years. Am J Gastroenterol 101: 255-262, 2006.

21. Leshno A, Moshkowitz M, David M, Galazan L, Neugut AI, Arber $\mathrm{N}$ and Santo E: Prevalence of colorectal neoplasms in young, average risk individuals: A turning tide between East and West. World J Gastroenterol 22: 7365-7372, 2016.

22. Hong SN, Kim JH, Choe WH, Han HS, Sung IK, Park HS and Shim CS: Prevalence and risk of colorectal neoplasms in asymptomatic, average-risk screenees 40 to 49 years of age. Gastrointest Endosc 72: 480-489, 2010.

23. Hemmasi G, Sohrabi M, Zamani F, Ajdarkosh H, Rakhshani N, Khoonsari M, Ameli M and Hatami K: Prevalence of colorectal adenoma in an average-risk population aged 40-50 Versus 50-60 years. Eur J Cancer Prev 24: 386-390, 2015.

24. Rundle AG, Lebwohl B, Vogel R, Levine S and Neugut AI: Colonoscopic screening in average-risk individuals ages 40 to 49 vs. 50 to 59 years. Gastroenterology 134: 1311-1315, 2008.

25. Imperiale TF, Wagner DR, Lin CY, Larkin GN, Rogge JD and Ransohoff DF: Results of screening colonoscopy among persons 40 to 49 years of age. N Engl J Med 346: 1781-1785, 2002. 
26. Mármol I, Sánchez-de-Diego C, Pradilla Dieste A, Cerrada E and Rodriguez Yoldi MJ: Colorectal carcinoma: A general overview and future perspectives in colorectal cancer. Int J Mol Sci 18: E197, 2017.

27. Pickhardt PJ, Kim DH, Pooler BD, Hinshaw JL, Barlow D, Jensen D, Reichelderfer $M$ and Cash BD: Assessment of volumetric growth rates of small colorectal polyps with CT colonography: A longitudinal study of natural history. Lancet Oncol 14: 711-720, 2013.

28. Müller MF, Ibrahim AE and Arends MJ: Molecular pathological classification of colorectal cancer. Virchows Arch 469: 125-134, 2016.

29. Hazewinkel Y, de Wijkerslooth TR, Stoop EM, Bossuyt PM, Biermann K, van de Vijver MJ, Fockens P, van Leerdam ME, Kuipers EJ and Dekker E: Prevalence of serrated polyps and association with synchronous advanced neoplasia in screening colonoscopy. Endoscopy 46: 219-224, 2014.

30. Ng SC, Ching JY, Chan VC, Wong MC, Tang R, Wong S, Luk AK, Lam TY, Gao Q, Chan AW, et al: Association between serrated polyps and the risk of synchronous advanced colorectal neoplasia in average-risk individuals. Aliment Pharmacol Ther 41: 108-115, 2015.

31. Weinberg BA, Marshall JL and Salem ME: The growing challenge of young adults with colorectal cancer. Oncology (Williston Park) 31: 381-389, 2017.

32. Hassan C, Pickhardt PJ, Kim DH, Di Giulio E, Zullo A, Laghi A, Repici A, Iafrate F, Osborn J and Annibale B: Systematic review: Distribution of advanced neoplasia according to polyp size at screening colonoscopy. Aliment Pharmacol Ther 31: 210-217, 2010 .
33. Altobelli E, Lattanzi A, Paduano R, Varassi G and di Orio F: Colorectal cancer prevention in Europe: Burden of disease and status of screening programs. Prev Med 62: 132-141, 2014.

34. Johnson DA, Barkun AN, Cohen LB, Dominitz JA, Kaltenbach T, Martel M, Robertson DJ, Boland CR, Giardello FM, Lieberman DA, et al: Optimizing adequacy of bowel cleansing for colonoscopy: Recommendations from the US multi-society task force on colorectal cancer. Gastroenterology 147: 903-924, 2014.

35. Steele RJ, Rey JF and Lambert R; International Agency for Research on Cancer: European guidelines for quality assurance in colorectal cancer screening and diagnosis. First Edition-Professional requirements and training. Endoscopy 44 (Suppl 3): SE106-SE115, 2012.

36. U.S. Preventive Services Task Force: Screening for colorectal cancer: U.S. Preventive Services Task Force recommendation statement. Ann Intern Med 149: 627-637, 2008.

37. Gondal G, Grotmol T, Hofstad B, Bretthauer M, Eide TJ and Hoff G: The norwegian colorectal cancer prevention (NORCCAP) screening study: Baseline findings and implementations for clinical work-up in age groups 50-64 years. Scand J Gastroenterol 38: 635-642, 2003.

38. Holme $\varnothing$, Bretthauer M, Eide TJ, Løberg EM, Grzyb K, Løberg M, Kalager M, Adami HO, Kjellevold $\varnothing$ and Hoff G: Long-term risk of colorectal cancer in individuals with serrated polyps. Gut 64: 929-936, 2015. 